Article abstract-The incidence, trend, and survivorship of ALS in the population of Rochester, Minnesota, was determined for the years 1925 through 1977 . The average annual incidence was 1.76 per 100,000 population. There was a small but nonsignificant increase in the rate during the 53-year period. The male:female ratio was 1.1, and the male:female ratio of incidence rates was 1.6 . The median age at onset was 66 years; the incidence rates increased with increasing age. Median survivorship was 22.5 months, and was longer for younger patients than for patients with an advanced age at onset. The demographic characteristics in this total community experience are believed to reflect the pattern of ALS more accurately than previously reported clinical series.

NEUROLOGY 30: 463-470, May 1980

\title{
ALS in Rochester, Minnesota, 1925-1977
}

Steven M. Juergens, M.D., Leonard T. Kurland, M.D., Dr.P.H., Haruo Okazaki, M.D., and Donald W. Mulder, M.D.

Amyotrophic lateral sclerosis (ALS), a motor neuron disease, has been the subject of many clinical and epidemiologic studies in an attempt to better understand its natural history and, ultimately, its cause.

ALS includes the clinical components of progressive muscular atrophy and progressive bulbar palsy. It is manifested in adult life as a progressive asymmetric muscular atrophy with weakness, wasting, and often fasciculations that may involve any of the striated muscles except extraocular and cardiac muscles.

Evidence of corticobulbar and pyramidal tract involvement includes hyperreflexia, positive palmomental responses, and the Babinski sign, but these may be masked by muscular atrophy. Other systems-such as sensory, extrapyramidal, mentation, and the system related to bladder function-are generally unaffected.

Rochester, Minnesota, offers a unique opportunity for long-term, relatively complete population studies of ALS. Since the early part of this century, the medical practice in Rochester has been centered largely at the Mayo Clinic. Each year, about half the local population is seen at our clinic, its affiliated hospitals, or at home, and all recorded diagnoses are indexed. About $60 \%$ of all residents who die undergo autopsy in our pathology department, and these diagnoses are also indexed. The records of the Mayo Clinic, together with those of other institutions of the community, are coded and stored in a composite medical diagnostic file, and so it is possible to identify practically all cases in which a serious illness has been diagnosed. The ability to study diseases in a circumscribed population over a long period afforded by this system offers a unique resource for epidemiologic study. The nearly complete case ascertainment makes it feasible to give a reliable description of the incidence and outcome of ALS without most of the selection bias of studies that are based solely on specialty-center patient populations, hospital records, questionnaires, or death certificates.

Recent investigations have reported a change in the age distribution ${ }^{1}$ and a longer clinical course ${ }^{2,3}$ for ALS, and one of us (D.W.M.) had the impression of a recent increase in the number of cases of ALS in the local community. In an attempt to clarify these reports and impressions, we expanded earlier studies of ALS in Rochester ${ }^{4,5}$ to include the impact of this disorder on the community during the past 53 years. We were specifically interested in evidence of changing incidence, age at onset, or duration of life, which might suggest an alteration in the cause and course of the disease or in our ability to treat the symptoms and complications.

Methods. We reviewed the unified records at the Mayo Clinic of all Rochester residents whose diagnoses were coded under a variety of categories compatible with ALS, including progressive muscular atrophy, bulbar palsy, and motor neuron disease. A resident was defined as any person whose domicile was within the city limits of Rochester for

From the Mayo Clinic and Mayo Foundation, Rochester, MN.

This investigation was supported in part by Research Grant No. G.M-14231 from the National Institutes of Health, Public Health Service, and from the St. Gerard Foundation.

Accepted for publication September 4. 1979.

Address correspondence and reprint requests to Dr. Kurland, Mayo Clinic, 200 First Street SW, Rochester, MN 55901. 
at least 1 year before the onset of symptoms. More than 500 patient records were retrieved from the medical indexing file, and were reviewed for possible inclusion in the study of the years 1925 through 1977. Autopsy records and death certificates were also examined, but these revealed no cases of ALS that were not already available from the medical index.

During the period 1925 through 1977,35 residents ( 18 males and 17 females) were identified with an accepted diagnosis of ALS. Only those who were residents of Rochester at onset were included. All but one patient were also residents of Rochester at the time of diagnosis (one patient had moved from Rochester to a nearby farm after he developed weakness and could no longer work as a mechanic, but this change occurred before he sought medical attention). All patients were seen and their condition diagnosed by at least one Mayo Clinic neurologist, and the records were subsequently reviewed by us. In 17 cases, there was autopsy confirmation of the diagnosis. Twenty-three patients had an electromyogram (EMG), and in all but 1 the findings were consistent with ALS. The one patient who had normal findings had only bulbar palsy at the time of the examination, and bulbar muscles were not tested on the EMG. Subsequently, autopsy showed findings consistent with ALS. Two additional residents probably had ALS, but they were subsequently excluded from analysis because review of the course and associated diseases suggested that they did not fulfill our diagnostic criteria.

Results. The mean annual incidence rates per 100,000 population were 2.1 for men, 1.6 for women, and 1.9 for the sexes combined (table 1). The rate, adjusted by age to the United states white population of 1950 , was 1.76 per 100,000 population. The observed incidence rates showed a slight increase during the 53-year period, but because of the small sample size, no conclusion concerning the trend can be made.
The numbers of males and females in the study were nearly the same, but because Rochester has a greater female population, the rates by sex, when adjusted to a standard population, show a higher rate for men. The age-adjusted incidence was 2.3 for men and 1.4 for women. The ratio of incidence rates for men to women was 1.6.

The age at onset of ALS ranged from 48 to 88 years, with a median of 66 years (figure 1 ). There was no significant difference in age at onset by sex. The median age at onset of the 18 men was 65.5 years, and the range was from 48 to 88 years. The median age at onset of the 17 women was 68 years, and the range was from 49 to 76 years.

The observed incidence rates increased with advancing age (table 2). However, the series is small, and, although suggestive, the rates in the age groups over 54 years did not differ significantly.

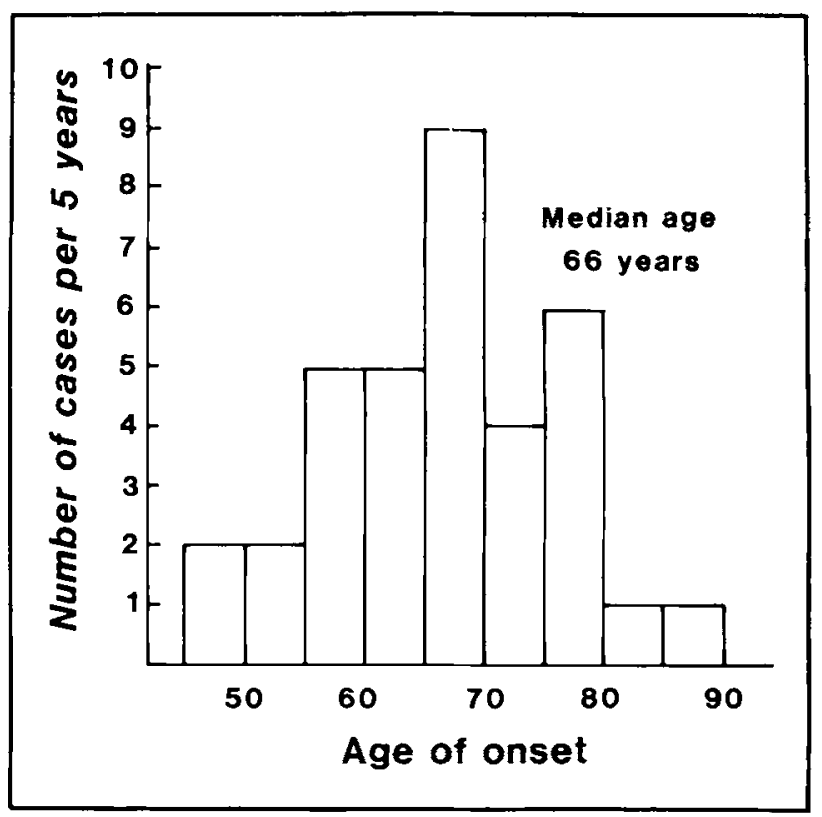

Figure 1. Ages at onset of ALS for 35 patients, Rochester, Minnesota, 1925 through 1977. 
Table 2. Incidence and average annual incidence rate by age for ALS: Rochester, Minnesota, 1925.1977

\begin{tabular}{|c|c|c|c|c|c|c|c|}
\hline \multirow[b]{2}{*}{$\begin{array}{l}\text { Year of } \\
\text { diagnosis }\end{array}$} & \multicolumn{2}{|c|}{ Males } & \multicolumn{2}{|c|}{ Females } & \multicolumn{2}{|c|}{ Total } & \multirow[b]{2}{*}{$\begin{array}{l}95 \% \text { confidence } \\
\text { interval total }\end{array}$} \\
\hline & $\begin{array}{l}\text { Number } \\
\text { of cases }\end{array}$ & Rate* & $\begin{array}{l}\text { Number } \\
\text { of cases }\end{array}$ & Rate* & $\begin{array}{l}\text { Number } \\
\text { of cases }\end{array}$ & Rate* & \\
\hline $1925-1954$ & 6 & 1.83 & 3 & 0.72 & 9 & 1.21 & $0.55-2.30$ \\
\hline $1955-1969$ & 6 & 2.11 & 7 & 2.02 & 13 & 2.06 & $1.10-3.52$ \\
\hline $1970-1977$ & 6 & 2.69 & 7 & 2.61 & 13 & 2.65 & $1.41-4.53$ \\
\hline Total & 18 & 2.15 & 17 & 1.65 & 35 & 1.88 & \\
\hline
\end{tabular}

The rate in the group 45 to 54 years of age was significantly $(p<0.01)$ less than that for the older groups.

The interval between the onset of symptoms and the first clinic visit ranged from 2 weeks to 62 months. The median interval was 7.5 months. Two patients waited more than 2 years before they had their symptoms evaluated. No significant sex difference was demonstrated for the interval from onset to first evaluation, although women tended to seek medical care a little sooner than men.

The survivorship curve of the 35 patients (figure 2) demonstrated that the median survivorship was 22.5 months. The range from onset to death was 9.5 months to 10 years. Two years after onset, the relative survivorship of those less than 65 years old at onset was $72 \%$, whereas for the older group it was $28 \%$. Two patients were still alive at last follow-up; one had survived 13.2 months and the other 32.9 months.

No patient in this series reported a family history of ALS.

There was no significant difference in median survivorship (21.2 versus 22.6 months) or median age at onset ( 66.5 versus 69 years) in patients who described bulbar symptoms at onset and patients who had limb weakness as the initial symptom.

Clinical and pathologic features. The clinical features at onset and during the course of illness were similar to those generally described for ALS. Details are included in the appendix table. All these patients exhibited pyramidal tract signs as well as signs of motor neuron degeneration on at least one neurologic examination. There was no case of progressive muscular atrophy. Eight patients described symptoms of bulbar musculature alone as their initial complaint, but only two exhibited bulbar signs alone at the time of the first neurologic examination, and only one patient had only bulbar signs through a second neurologic examination. However, even the latter patient showed evidence of more widespread motor neuron involvement at postmortem.

Sensory symptoms (pain) were noted by several patients (seven patients, or $20 \%$, on the first examination; three patients, or $10 \%$, on the second examination). Sensory signs, predominantly loss of distal vibration sense, were also noted in several patients but were felt to be compatible with their age.

Eighteen of the 33 patients who died underwent autopsy. Fourteen autopsies were done at the Mayo Clinic; the findings were reviewed by one of us (H.O.) and were compatible with ALS. All 14 autopsies revealed anterior horn cell degeneration, and 8 also showed definite pyramidal tract demyelination; the other 6 showed predominantly anterior horn cell involvement. Of the four cases in which autopsy was done at other institutions, there were no neuropathology reports or specimen sections in one case; in the other three cases, the reports described the changes of ALS. In two of these, specimen sections were reviewed and revealed anterior horn cell degeneration and, in one case, demyelination of the long motor tracts. In the autopsies we reviewed, there were no abnormalities in the posterior columns, Clark's column, or spinocerebellar tract, nor were any neurofibrillary tangles or hyaline inclusions found in the spinal cord.

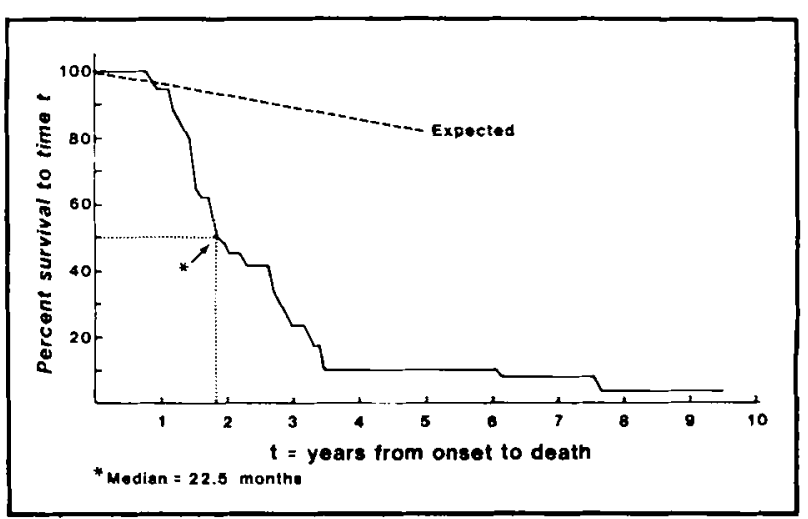

Figure 2. Survival of 35 patients with ALS, Rochester, Minnesota, 1925 through 1977, compared with expected survival. 
For $30(91 \%)$ of the 33 deceased patients, the death certificates listed ALS as a cause of death. One death certificate noted "ascending paralysis of the lower extremities" as a contributory cause, and two reports made no mention of any neurologic abnormality. Twenty-six of the 30 had ALS listed as the primary cause of death, and the others had it listed as a contributory cause. In view of the high correlation between certification of cause of death and clinical diagnosis, it should be noted that most of the Rochester death certificates were completed by Mayo Clinic pathologists who had access to the patients' medical records as well as the pathologic findings when the autopsy was done.

The appendix includes a list of occupations of the patients and an account of prior and associated injuries, diseases, toxins, and radiation.

Discussion. Rochester, Minnesota, has been the source of previous but more limited studies on the epidemiology of ALS.4.5 In the present study, we extended the period covered from 40 to 53 years; because of the rapid growth of the Rochester population, this increased the number of patients from 17 to 35.

The average annual incidence per 100,000 population, age-adjusted to the 1950 United States white population, was 1.8 . These results are slightly higher than those reported in the previous Rochester study, in which the rate was 1.3. Zack, Levitt, and Schoenberg ${ }^{6}$ identified 31 patients with ALS and reported an incidence of 1.3 per 100,000 population for Lehigh County, Pennsylvania, between 1968 and 1975; theirs is the only other incidence study from the continental United States. In other studies from Hawaii, Europe, Israel, and Mexico, the reported rates varied from 0.2 to 1.4 per 100,000 (table 3). Lower incidence figures were reported in European and Mexican studies, but case ascertainment may have been incomplete because of the hospital-based methods employed. ${ }^{15}$ However, none of the North American and European incidence rates approach those of Guam $^{16}$ and the Kii Peninsula of Japan. ${ }^{17}$

The observed incidence rates in Rochester increased with increasing age, but in the small series the increase in the subgroups over 55 years of age was not statistically significant. Many series from referral centers have noted a decline in the number of patients after about age $55,{ }^{19.20}$ but these do not include reference to the populations at risk and cannot be interpreted in a manner applicable to rates. Kurland, Choi, and Sayre ${ }^{5}$ examined the United States mortality figures for 1959 to 1961 and found that the age-specific rates for ALS also increased with age and reached a peak at about 70 years for white men and women and nonwhite men and then declined. Whether the agespecific rates for ALS do increase with age throughout adult life is still open to question.

Our study covered 53 years; there was a slight but not statistically significant increase in the incidence rates during this time. There was no increase in the proportion of younger subjects as reported by Aimard and associates. ${ }^{1}$

The male:female ratio of age-adjusted rates was 1.6. This ratio is smaller than the 2 to 2.5 ratio given in some clinical series. ${ }^{18-20}$ Population

Table 3. Population surveys of motor neuron disease

\begin{tabular}{|c|c|c|c|c|c|}
\hline Source & $\begin{array}{c}\text { Years } \\
\text { of } \\
\text { study }\end{array}$ & Location & $\begin{array}{c}\text { Base } \\
\text { population }\end{array}$ & $\begin{array}{l}\text { Total } \\
\text { cases }\end{array}$ & $\begin{array}{c}\text { Annual } \\
\text { incidence } \\
\text { per } \\
100,000\end{array}$ \\
\hline Current report & $1925-1977$ & Rochester, MN & 36,665 & 35 & 1.76 \\
\hline Lorez $^{7}$ & $1951-1967$ & NW Switzerland & 300,000 & 89 & 1.4 \\
\hline Zack, Levitt, and Schoenberg ${ }^{8}$ & $1968-1975$ & Lehigh Co., PA & 255,304 & 31 & 1.32 \\
\hline Kurland and associates 4.5 & $1925-1964$ & Rochester, MN & 30,000 & 17 & 1.34 \\
\hline Matsumoto and co-workers ${ }^{8}$ & $1952-1969$ & Hawaii & 632,772 & 118 & 1.04 \\
\hline Brewis and associates ${ }^{9}$ & $1955-1961$ & Carlisle, England & 71,000 & 5 & 1.0 \\
\hline Kahana, Alter, and Feldman ${ }^{10}$ & $1960-1970$ & Israel & $2,360,066$ & 185 & 0.78 \\
\hline Cendrowski, Wender, and Owsianowski"1 & $1955-1965$ & Poznan, Poland & $2,547,736$ & 56 & 0.22 \\
\hline Gudmundsson ${ }^{12}$ & $1954-1963$ & Iceland & 187,200 & 24 & 0.76 \\
\hline Rosati and associates ${ }^{13}$ & $1965-1974$ & Sardinia & $1,494,084$ & 96 & 0.64 \\
\hline Olivares, San Estéban, and Alter ${ }^{14}$ & $1962-1969$ & ISSTE population, Mexico City & 494,059 & 16 & 0.40 \\
\hline
\end{tabular}


studies have given conflicting results, as would be expected when the total number of cases is small. Most series report a preponderance of men. ${ }^{10-13,21}$ The sex ratio of our population was similar to that given in the United States mortality rates for ALS $^{5}$ and the National ALS Foundation Registry. ${ }^{2}$ Our data showed a continued strong male predominance in the incidence rates of those age 65 or older (1.87:1), whereas the National ALS Foundation Registry showed a 1:1 ratio in the incidence rates for those older than 65 years.

None of the cases in our small series reported a familial history of ALS. Reports from clinical series ${ }^{2,22}$ indicate that about $5 \%$ to $10 \%$ of patients with ALS have a family history; these are usually compatible with an autosomal dominant pattern of inheritance. However, those reports may reflect greater awareness of the disease in members of affected families, who in turn may seek medical care in the type of referral centers from which clinical publications emanate.

The age at onset of ALS ranged from 48 to 88 years, with a median of 66 years; there was little difference by sex. These results are consistent with the previous Rochester study 5 and argue for an average age at onset several years older than the late forties to middle fifties reported in several clinical series $2,18-20.23$ and most population studies. ${ }^{6 \cdot 10.12-14.21}$

Comparison of the patients in this Rochester study with two Mayo Clinic series ${ }^{19.24}$ of largely referred ALS patients clearly shows the differences in age at onset. In an earlier Mayo Clinic series of 100 patients seen in the mid-1950s, ${ }^{19}$ the median age at onset was 52 years, 4 were less than 50 years old, and $76 \%$ were less than 60 years. In a recent unpublished series ${ }^{24}$ of 117 other patients seen since 1975 , the median age was 59 years; $31 \%$ were less than 50 years, $54 \%$ were less than 60 years, and $73 \%$ were less than 65 years old at onset. However, in the present study of 35 ALS patients from Rochester, only 5\% had onset before age 50 years, $20 \%$ before age 60 , and $40 \%$ before age 65.

It is difficult to be sure of the site first affected. We found no difference in prognosis or age at onset in patients with bulbar symptoms at onset. However, by history, the three patients who lived longer than 5 years after onset did not have bulbar symptoms first, and the two patients with a rapid course did have oropharyngeal symptoms first. In other series ${ }^{\mathbf{2 . 3 . 2 3}}$ patients with bulbar onset had a poorer prognosis and an older age at onset, although this was not substantiated in the first Mayo Clinic series. ${ }^{22}$

The median survivorship for the Rochester patients was 22.5 months. Patients age 65 and over, as expected, had shorter survival than the younger group. When this difference in survivorship is adjusted for expected mortality, it is small and not statistically significant. A similar relationship was noted by others. ${ }^{2,10.13 .14 .23}$

The survivorship of $50 \%$ at 22.5 months was less than that reported in most clinical series, ${ }^{2,3,18,23}$ and partially reflected the number of older patients. Elderly patients may also have greater difficulty recalling the earlier manifestations, and this could account in part for the shorter duration reported.

Mulder and Howard ${ }^{3}$ found that $20 \%$ of 100 ALS patients were alive after 5 years, and Rosen ${ }^{2}$ found a 5-year survival of $39.4 \%$ on the basis of questionnaires to 596 patients. In the present series, the 5-year survival, as estimated with two persons still living (both less than 2 years after diagnosis), was $9 \%$ and ultimately cannot exceed $14.3 \%$. Our population was significantly older, and this may have contributed to the reduced longevity.

The wide variations of average age at onset and duration of ALS have been attributed to differences in study design. For example, Jokelainen ${ }^{21}$ in Finland compared living patients and patients identified through death certificates; the living patients were younger and also had a longer duration of disease then the patients who died. $\mathrm{He}$ believed that there was some selective loss (by the time the death certificates were written) of cases with earlier age at onset and slower course. In our study, cases with longer course or onset at an earlier age were as likely to be reported as ALS on the death certificate.

Most published studies of ALS were based on patients seen at specialty centers. Patients referred from a distance to the specialty centers must of necessity live long enough to obtain appointments and be able to travel. Patients with rapidly advancing disease may not be included to the same extent as patients with an indolent course. The age of the patient may also introduce bias. If the patient is young, the family or local physician may be more motivated to obtain a specialist's opinion. Elderly patients may have more difficulty traveling to a specialty center because of the limitations associated with age as well as the debilitation of ALS. Also, the family, local physician, or patient may assume that the symptoms are part of the aging process and not worth seeking further opinion. This should not apply to the Rochester patients, who would almost certainly be referred to a Mayo Clinic neurologist. A similar bias in clinical series toward the selection of younger patients with a longer course has also been observed in other conditions, such as parkinsonism. ${ }^{25,26}$

One study of ALS was based on questionnaires from patient-members of a voluntary agency. ${ }^{2} \mathrm{~Pa}$ tients who join voluntary ALS organizations are more likely to be white, younger, and from higher socioeconomic levels and urban centers, and have a longer duration of disease than those who do not join. Patients who are severely debilitated early 
and have rapidly advancing disease are less likely to survive long enough to learn about the agency or to join and participate in such studies.

Surveys using death certificates should be less selective and, as such, give evidence of a disease process that begins, on the average, later in life than those represented in specialty centers. Examining the national distribution of ages at death supports this view. Kurland, Choi, and Sayre 5 found that for ALS-certified deaths in the United States from 1959 through 1961, the mean age was 64.4 years and the median age was 62 years. Assuming a 3- to 4-year average duration from onset to death, the age at onset would then be approximately 60 years, or between the age noted in most clinical series and the age in this population-based study.

\section{Acknowledgments}

The authors thank Mary E. Ziegler, Laura Long, Karen Elias, Margaret A. Kennedy, Shirley A. Fortney, and James R. Wentz for their technical assistance.

\section{References}

1. Aimard G, Bady B, Boisson D, et al: Amyotrophic lateral sclerosis with onset before the age of $\mathbf{4 0}$ years: Remarks regarding 25 cases. (NIH Library Translation NIH-78-193). Rev Neurol (Paris) 132:563-566, 1976

2. Rosen AD: Amyotrophic lateral sclerosis: Clinical features and prognosis. Arch Neurol 35:638-642, 1978

3. Mulder DW, Howard FM Jr: Patient resistance and prognosis in amyotrophic lateral sclerosis. Mayo Clin Proc 51:537-541, 1976

4. Kurland LT: Descriptive epidemiology of selected neurologic and myopathic disorders with particular reference to a survey in Rochester, Minnesota. J Chronic Dis 8:378-418, 1958

5. Kurland LT, Choi NW, Sayre GP: Implications of incidence and geographic patterns on the classification of amyotrophic lateral sclerosis. In Norris FH Jr, Kurland LT (Editors): Motor Neuron Diseases: Research on Amyotrophic Lateral Sclerosis and Related Disorders. New York, Grune \& Stratton, Inc, 1969, pp 28-50

6. Zack MM, Levitt LP, Schoenberg B: Motor neuron disease in Lehigh County, Pennsylvania: An epidemiologic study. J Chronic Dis 30:813-818, 1977

7. Lorez A: Ein Beitrag zu Klinik und Vorkommen der amyotrophischen Lateralsklerose (isolierte and familiäre Fälle) Schweiz Med Wochenschr 99:51-57, 1969

8. Matsumoto N, Worth RM, Kurland LT, et al: Epidemiologic study of amyotrophic lateral sclerosis in Hawaii: Identification of high incidence among Filipino men. Neurology (Minneap) 22:934-940, 1972

9. Brewis M, Paskanzer DC, Rolland C, et al: Neurological disease in an English city. Acta Neurol Scand 42 [suppl 24 ]: $1-89,1966$

10. Kahana E, Alter M, Feldman S: Amyotrophic lateral sclerosis: A population study. J Neurol 212:205-213, 1976

11. Cendrowski W, Wender M, Owsianowski M: Analyse epidemiologique de la sclerose laterale amyotrophique sur le territoire de la Grande-Pologne. Acta Neurol Scand 46:609-617, 1970
12. Gudmundsson KR: The prevalence of some neurological diseases in Iceland. Acta Neurol Scand 44:57-69, 1968

13. Rosati G, Pinna L, Granieri E, et al: Studies on epidemiological, clinical and etiological aspects of ALS disease in Sardinia, Southern Italy. Acta Neurol Scand 55:231-244, 1977

14. Olivares L, San Estéban E, Alter M: Mexican "resistance" to amyotrophic lateral sclerosis. Arch Neurol 27:397-402, 1972

15. Bobowick AR, Brody JA: Epidemiology of motor-neuron diseases. N Engl J Med 288:1047-1055, 1973

16. Chen K, Brody JA, Kurland LT: Patterns of neurologic diseases on Guam: I. Epidemiologic aspects. Arch Neurol 19:573-578, 1968

17. Yase Y, Matsumoto N, Yoshimasu F, et al: Motor neuron disease in the Kii Peninsula, Japan. Prac Aust Assoc Neurol 5:335-339, 1968

18. Mackay RP: Course and prognosis in amyotrophic lateral sclerasis. Arch Neurol 8:117-127, 1963

19. Mulder DW: The clinical syndrome of amyotrophic lateral sclerosis. Proc Staff Meet Mayo Clin 32:427-436, 1957

20. Friedman AP, Freedman D: Amyotrophic lateral sclerosis. $J$ Nerv Ment Dis 111:1-18, 1950

21. Jokelainen M: Amyotrophic lateral sclerosis in Finland: I. An epidemiologic study. Acta Neurol Scand 56:185-193, 1977

22. Mulder DW, Espinosa RE: Amyotrophic lateral sclerosis: Comparison of the clinical syndrome in Guam and the United States. In Norris FH Jr, Kurland LT (Editors): Motor Neuron Diseases: Research on Amyotrophic Lateral Sclerosis and Related Disorders. New York, Grune \& Stratton, Inc, 1969, pp 12-19

23. Boman K, Meurman T: Prognosis of amyotrophic lateral sclerosis. Acta Neurol Scand 43:489-498, 1967

24. Mulder DW: Unpublished data

25. Nobrega FT, Glattre E, Kurland LT, et al: Comments on the epidemiology of parkinsonism including prevalence and incidence statistics for Rochester, Minnesota, 1935-1966. Excerpta Medica International Congress Series No. 175, 1969, pp 474-485

26. Kurland LT, Darrell RW: Epidemiologic and genetic characteristics of parkinsonism: A review. Int $J$ Neurol $2: 11-24,1961$

Appendix. In reviewing the Mayo Clinic records, one patient was excluded and three patients were added to the series reported by Kurland, Choi, and Sayre ${ }^{5}$ for the period 1925 to 1964 . One patient was excluded because she had not been a resident of Rochester for 1 year before diagnosis. Three patients were added. One was a physician who, at 75 years of age, had had bulbar palsy of rapid onset. Neurologists at the Mayo Clinic agreed that he had ALS and that the pathologic data were consistent with ALS. In two additional patients, ALS developed during the survey period of the last study, but at the time of that study a positive diagnosis of ALS had not been established.

Occupation. The occupations, as listed for both men and women in this medical community, showed no obvious selection with respect to socioeconomic status or possible hazard at work (appendix table). Among the females, there were seven housewives, three nurses, two other hospital workers, a teacher, a seamstress, a milliner, a cashier, and an elevator operator. Among the males, there were four unskilled laborers, two semiskilled laborers, two salesmen, two restau- 
Appendix table. Demographic, clinical, and pathologic features of ALS patients, Rochester, Minnesota, 1925-1977

\begin{tabular}{|c|c|c|c|c|c|c|c|c|c|c|c|c|c|c|}
\hline \multirow[b]{2}{*}{$\begin{array}{l}\text { Pattont } \\
\text { mambor }\end{array}$} & \multirow[b]{2}{*}{ Sex } & \multirow[b]{2}{*}{ Uoual occupatton } & \multirow{2}{*}{$\begin{array}{l}\text { Year } \\
\text { of } \\
\text { birth }\end{array}$} & \multirow{2}{*}{$\begin{array}{c}\text { Date } \\
\text { at } \\
\text { oneeh, } \\
\text { mo/yr }\end{array}$} & \multirow{2}{*}{$\begin{array}{l}\text { Firot Mayo } \\
\text { Clinic } \\
\text { neurologic } \\
\text { examinatiod, } \\
\text { molyr }\end{array}$} & \multirow{2}{*}{$\begin{array}{c}\text { Date of } \\
\text { diegnoals, } \\
\text { mo/yr }\end{array}$} & \multirow{2}{*}{$\begin{array}{c}\text { Age at } \\
\text { onseth } \\
\text { yra }\end{array}$} & \multirow{2}{*}{$\begin{array}{c}\text { Laot Mayo } \\
\text { Clinic } \\
\text { neurologic } \\
\text { examination, } \\
\text { mo/yr }\end{array}$} & \multirow{2}{*}{$\begin{array}{l}\text { Date of } \\
\text { death or } \\
\text { lant } \\
\text { follow-up, } \\
\text { mo/yr }\end{array}$} & \multirow{2}{*}{$\begin{array}{c}\text { Daration } \\
\text { (oneet } \\
\text { to } \\
\text { denth), } \\
\text { mo }\end{array}$} & \multicolumn{4}{|c|}{ Potmorten } \\
\hline & & & & & & & & & & & EMG & No & Cleadical & $\begin{array}{l}\text { PMA } \\
\text { PBP }\end{array}$ \\
\hline 1 & $\mathbf{F}$ & Housewife & 1878 & $5 / 28$ & $6 / 29$ & $3 / 31$ & 49 & $2 / 31$ & $3 / 31$ & 35 & & & $\mathrm{x}$ & \\
\hline 2 & $M$ & Minioter & 1873 & $9 / 29$ & $10 / 30$ & $10 / 30$ & 55 & $4 / 32$ & $4 / 32$ & 31 & & & $\mathrm{x}$ & \\
\hline 3 & $M$ & Maintenance worker & 1873 & $6 / 39$ & $6 / 40$ & $6 / 40$ & 66 & - & $12 / 40$ & 18 & & & & $\mathbf{x}$ \\
\hline 4 & $\mathbf{M}$ & Gerdener & 1872 & $12 / 41$ & $12 / 42$ & $12 / 42$ & 69 & - & 6/43 & 17 & & & $\mathrm{x}$ & \\
\hline 5 & $\mathbf{M}$ & Phywician & 1866 & $7 / 42$ & $11 / 42$ & $11 / 42$ & 76 & $10 / 43$ & $10 / 43$ & 16 & & & & $\mathrm{x}$ \\
\hline 6 & $\boldsymbol{F}$ & Milliner & 1870 & 2/45 & $10 / 45$ & $10 / 45$ & 74 & $3 / 46$ & $7 / 46$ & 17 & & $\mathrm{x}$ & & \\
\hline 7 & $\mathrm{M}$ & Farmericity dump worker & 1883 & 4/52 & $3 / 54$ & $3 / 54$ & 69 & 2/55 & 6/55 & 38 & + & $\mathbf{x}$ & & \\
\hline 8 & $\mathbf{F}$ & Liceneed practical nurse & 1876 & $12 / 52$ & $11 / 53$ & $12 / 53$ & 76 & $12 / 53$ & 5/54 & 17 & & & $\mathrm{x}$ & \\
\hline 9 & $\mathbf{M}$ & Dog catcher & 1905 & 3/54 & $12 / 34$ & $12 / 54$ & 48 & $7 / 57$ & $8 / 57$ & 41 & & & $\mathbf{x}$ & \\
\hline 10 & $\mathbf{M}$ & Horre trainer & 1890 & $1 / 55$ & $7 / 56$ & $2 / 57$ & 64 & $2 / 5 ?$ & $6 / 58$ & 41 & + & $\mathrm{x}$ & & \\
\hline 11 & $\boldsymbol{r}$ & Housewife & 1888 & $? / 57$ & $10 / 62$ & $10 / 62$ & 69 & $11 / 65$ & 5/67 & 119 & + & $\ddot{x}$ & & \\
\hline 12 & $\boldsymbol{F}$ & Housenife & 1890 & $7 / 81$ & $4 / 62$ & 4/62 & 70 & 9,62 & $5 / 63$ & 23 & + & $\mathbf{x}$ & & \\
\hline 13 & $\mathbf{M}$ & Bookktkoper/stockroom clerk & 1901 & $12 / 61$ & 1261 & 3/62 & 60 & 6/83 & $6 / 63$ & 18 & + & & $\mathrm{x}$ & \\
\hline 14 & $\mathbf{F}$ & Toacher & 1900 & $12 / 81$ & $3 / 62$ & $12 / 62$ & 61 & 2/BA & $7 / 64$ & 31 & + & $\mathbf{x}$ & & \\
\hline 15 & $\boldsymbol{F}$ & Hoopital maid & 1893 & $2 / 62$ & $5 / 62$ & $8 / 62$ & 68 & $8 / 82$ & $4 / 64$ & 26 & + & $\hat{x}$ & & \\
\hline 18 & $\mathbf{x}$ & Auto mechanic & 1903 & 7,62 & 7/67 & $7 / 67$ & 59 & - & $7 / 88$ & 72 & & & $\mathrm{x}$ & \\
\hline 17 & M & Garbage collector/truck driver & 1893 & 7163 & 1/65 & 1/65 & 70 & 4/65 & $4 / 65$ & 21 & + & $\mathrm{x}$ & & \\
\hline 18 & $\mathbf{F}$ & Housewife & 1888 & 4/64 & 1264 & $12 / 64$ & 75 & $1 / 86$ & $4 / 66$ & 24 & + & & $\mathrm{x}$ & \\
\hline 19 & M & Retired farmer/grain buyer & 1876 & $5 / 64$ & $7 / 65$ & $7 / 65$ & 88 & - & $7 / 65$ & 14 & + & & - & \\
\hline 20 & $\mathbf{F}$ & Elevator operator & 1892 & 1266 & $1 / 66$ & $3 / 66$ & 73 & $8 / 67$ & $8 / 87$ & 21 & & & & $\mathbf{x}$ \\
\hline 21 & $\mathbf{F}$ & Hounewife & 1890 & $10 / 67$ & $11 / 67$ & $5 / 68$ & 76 & $5 / 88$ & 8770 & 34 & + & $\mathrm{x}$ & & \\
\hline 22 & $\mathbf{M}$ & Hoopital laundry worker & 1907 & $10 / 67$ & $5 / 68$ & $5 / 68$ & 60 & $9 / 68$ & 2/69 & 16 & + & & & $\mathbf{x}$ \\
\hline 23 & $\mathbf{M}$ & Retirod car nelesman & 1903 & $10 / 68$ & 9/69 & $1 / 70$ & 65 & $6 / 70$ & $7 \pi 70$ & 21 & $-\ddagger$ & & & $\mathrm{x}$ \\
\hline 24 & $\mathbf{F}$ & Regintered nurse & 1918 & 2169 & $5 / 69$ & $10 \pi 0$ & 50 & $1 / 71$ & $4 / 72$ & 38 & + & & $\mathrm{x}$ & \\
\hline 25 & $M$ & Laborer & 1917 & 1270 & $5 / 71$ & $5 / 71$ & 53 & $2 \pi 2$ & 472 & 16 & + & & & $\mathrm{x}$ \\
\hline 26 & $\boldsymbol{F}$ & Seametroen & 1902 & $4 / 71$ & $5 / 72$ & $5 / 72$ & 68 & - & $10 / 78$ & 86 & + & $\mathrm{x}$ & & \\
\hline 27 & $\boldsymbol{F}$ & Registered nurse & 1908 & $3 \pi 2$ & $4 / 72$ & 472 & 63 & - & $9 / 73$ & 18 & + & $\mathrm{x}$ & & \\
\hline 28 & M & Retined reateurant owner & 1896 & $6 / 73$ & $1 / 74$ & $5 / 74$ & 78 & $5 / 74$ & $7 \pi 4$ & 13 & & $\mathbf{x}$ & & \\
\hline 29 & $\mathbf{M}$ & Engineer & 1896 & $9 / 4$ & $10 / 74$ & $7 / 75$ & 77 & $7 \pi 8$ & $8 / 75$ & 11 & + & & & $\mathrm{x}$ \\
\hline 30 & $\mathbf{F}$ & Hoopital clerk & 1920 & $6 / 75$ & $1 / 76$ & $10 \pi 7$ & 55 & $10 \pi 7$ & $2 / 78$ & 32 & + & $\mathrm{x}$ & & \\
\hline 31 & $\mathbf{F}$ & Hounewife & 1920 & $11 / 76$ & $5 / 76$ & $6 / 78$ & 55 & $10 / 77$ & 678 & 31 & + & $\hat{x}$ & & \\
\hline 32 & $\mathrm{~F}$ & Cashier & 1918 & $3 / 78$ & $7 \pi 6$ & $9 / 77$ & 58 & $9 / 77$ & $12 / 78^{\circ}$ & $25^{\circ}$ & + & $\mathbf{A}$ & & \\
\hline 33 & M & Real extate seleoman & 1911 & $11 / 76$ & $6 / 77$ & $5 / 77$ & 65 & - & 878 & 17 & + & $\mathbf{x}$ & & \\
\hline 34 & M & Retired cook & 1893 & $3 / 77$ & 1277 & $12 / 77$ & B4 & - & $12 / 77$ & 10 & & & $\mathrm{x}$ & \\
\hline 35 & $\mathbf{F}$ & Houneswife & 1910 & $11 / 77$ & $3 / 78$ & $3 \pi 8$ & 67 & $6 / 78$ & $12 / 78^{*}$ & 9 & + & & & \\
\hline
\end{tabular}

rant workers, a hospital laundry worker, a dog catcher, a horse trainer, a grain buyer, an engineer, a bookkeeper, a minister, and a physician.

Injuries. The nature of the medical records for this population provides unusually complete documentation of injuries and other prior or subsequent events that might be considered of etiologic importance or as sequelae of ALS. For many such conditions we do not yet have incidence rates to provide a basis for comparison, but it appears that for some of the items to be described, the condition or event could well be coincidental.

Three patients had injuries that were previous and proximate to the onset of ALS. One patient injured her right shoulder in January 1963 and developed adhesive capsulitis and tendinitis. After a steroid injection, there was considerable improvement until March 1963, when she noted more pain; in November 1965, she noted weakness in the right shoulder and both hands, and ALS was diagnosed in March 1966.

Another patient fell on his right shoulder in 1935 and then fractured his right glenoid fossa in January 1952. Three months later, in April 1952, the patient noted a slowly progressive weakness in the same extremity from the ALS.

One patient was in an automobile that decelerated rapidly, resulting in an injury, with pain and loss of mobility of the left upper extremity. It was considered to be a "possible cervical disk." There was some improvement for 2 years after the accident, when progressive weakness and wasting were noted in the same extremity, and weakness, wasting, and EMG changes also were noted in one of the lower extremities; ALS was diagnosed.

Surgery and anesthesia. Another patient had a left total hip arthroplasty on September 17, 1974. Neurologic examination on October 31 revealed atrophy of the left anterior tibialis muscle and a footdrop. The patient claimed to have had no weakness before his operation, but after he was released from the hospital, he noted progressive trouble with secretions and speech, and lower extremity weakness. ALS was diagnosed in July 1975.

Two of the patients had had known spinal anesthesia within 10 years of onset of ALS, one for a transurethral resection in May 1968 (onset of ALS 
in March 1977) and the other for hemorrhoidectomy and polyp fulguration in September 1965 (onset of ALS in October 1968).

Malignancy. Five patients had malignant neoplasms before the onset of ALS. Two patients had basal cell epitheliomas of the skin successfully removed, and another patient had a grade 2 squamous cell epithelioma removed from his left vocal cord. Another had a grade 3 hypernephroma removed with no clinical recurrence. One patient had three primary malignant lesions within $3 \frac{112}{12}$ years of the onset of ALS. In September 1965, she had a left radical mastectomy for grade 4 scirrhous adenocarcinoma. In January 1966 , she had a right simple mastectomy for lobular carcinoma in situ of the right breast. In April 1966, a subtotal thyroidectomy was performed for a grade 1 follicular carcinoma of the thyroid. Bulbar symptoms of ALS developed in February 1969.

Thyroid. Ten patients had histories of thyroid abnormalities previous to the onset of ALS. On the patients' histories it was noted that three patients had thyroid nodules and one patient had hypothyroidism. Two patients had exophthalmic goiters, of which one was treated by surgery and the other was treated with ${ }^{131}$ I and subsequently became myxedematous. One patient had a nontoxic goiter, and another had a multinodular goiter. One patient had a grade 1 follicular carcinoma with subtotal thyroidectomy (described in the preceding paragraph).

Previous neurologic diseases. One patient had an essential familial tremor and temporal lobe seizures in 1969, and manifested symptoms of ALS in April 1971. Two patients had histories of migraine headaches. Another patient had signs and symptoms of unilateral parkinsonism, particularly in the right upper extremity, in 1939, 22 years before the onset of ALS. Weakness and wasting began in the same extremity in which the tremor and rigidity had been present. Death occurred 31 months after the onset of ALS. At autopsy, the patient had classic signs of ALS and also had atrophy of the left substantia nigra and diffuse cortical degeneration with gliosis.

Miscellaneous. One patient suffered nonspecific pains in the neck and shoulders in March 1961, after a mild episode of the flu. She continued to suffer from a chronic cough, shoulder and neck pain, exhaustion, and hypochromic anemia, and had sedimentation rates as high as $150 \mathrm{~mm}$ in 1 hour. A diagnosis of either secondary myositis or polymyositis was considered. The patient slowly improved during the next 6 to 8 months. Bulbar palsy developed in April 1964.

There appeared to be no excess of cases of stroke (one patient), diabetes (two patients), or hyperparathyroidism (one patient).

Toxins. Two patients had histories of exposure to toxins; whether this is a factor in ALS is undetermined. One was a stockroom employee in a laboratory who had been exposed to numerous solvents, including carbon tetrachloride and ammonia. The other patient was the city dog catcher, who worked with cyanide gas until 4 years before the onset of ALS.

Radiation. Six patients received irradiation before the onset of ALS. One patient was given 11 treatments of radiation to the left side of the neck, left shoulder, and left upper extremity from March to May 1940 for myositis or neuritis in his left shoulder. Bulbar palsy developed in July 1942. One patient received $52 \mu \mathrm{Ci}$ of ${ }^{131} \mathrm{I}$ for an exophthalmic goiter in September 1952; ALS developed in June 1961, beginning in his left leg. One patient received about 140 rads for pain in his left knee in 1940; lower-extremity weakness and bulbar palsy developed in October 1967. One patient received 373 rads in 3 days to a small area of the dorsum of his right arm in June 1963 for possible sporotrichosis. ALS developed with initial bulbar palsy in March 1977. One patient had a radium implant overnight for menorrhagia in 1933, and bulbar palsy developed in April 1964. In 1948, one patient had about 5 rads to her right shoulder for subdeltoid bursitis; ALS developed in 1969, with initial manifestations of left shoulder weakness.

The rate of radiation exposure in the population of Rochester is not available. However, it is our impression that among the population of the same age distribution, therapeutic radiation was widely applied in the past. Thus, we cannot conclude that this group of patients had any significant excess of such radiation exposure. 


\section{Neurology}

ALS in Rochester, Minnesota, 1925-1977

Steven M. Juergens, Leonard T. Kurland, Haruo Okazaki, et al.

Neurology 1980;30;463

DOI 10.1212/WNL.30.5.463

\section{This information is current as of May 1,1980}

\section{Updated Information \& Services}

\section{Citations}

Permissions \& Licensing

Reprints including high resolution figures, can be found at: http://n.neurology.org/content/30/5/463.full

This article has been cited by 10 HighWire-hosted articles: http://n.neurology.org/content/30/5/463.full\#\#otherarticles

Information about reproducing this article in parts (figures,tables) or in its entirety can be found online at:

http://www.neurology.org/about/about_the_journal\#permissions

Information about ordering reprints can be found online:

http://n.neurology.org/subscribers/advertise

Neurology ${ }^{\circledR}$ is the official journal of the American Academy of Neurology. Published continuously since 1951, it is now a weekly with 48 issues per year. Copyright (C) 1980 by the American Academy of Neurology. All rights reserved. Print ISSN: 0028-3878. Online ISSN: 1526-632X.

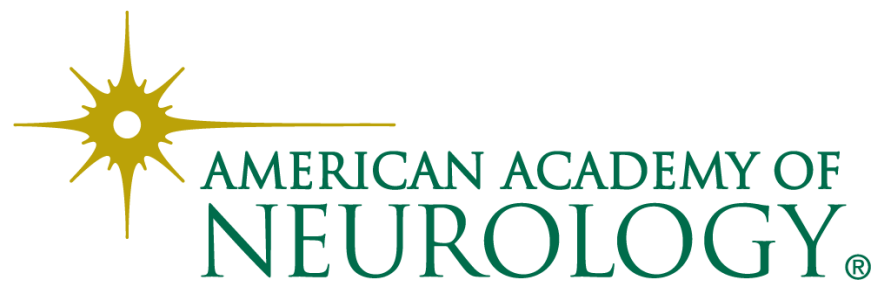

